\title{
OS DESAFIOS DO ENSINO DE PLAC PARA OS INDÍGENAS WARAO EM BELÉM
}

\author{
THE TEACHING OF PORTUGUESE AS A WELCOME LANGUAGE FOR \\ THE VENEZUELAN INDIGENOUS WARAO
}

\author{
Ana Paula Barros Brandão ${ }^{1}$ \\ Flávio Amauri Machado da Silva² \\ Samily Soares dos Santos ${ }^{3}$
}

\section{Resumo}

$\mathrm{O}$ artigo tem como objetivo apresentar uma experiência de ensino de PLAc para os indígenas Warao, em projeto de extensão da Universidade Federal do Pará (que teve início em janeiro e término em dezembro de 2018). Desde 2014, os Warao estão migrando da Venezuela para o Brasil por causa da crise econômica no país deles. Com o fim de favorecer as relações entre os Warao e a sociedade brasileira, começamos a ensinar português para eles no abrigo onde moravam. Para o ensino de PLAc, utilizamos das abordagens comunicativa e intercultural com base em autores como Caels (2016), Lopez (2016), Costa e Taño (2017), Cardoso (2018), São Bernardo e Barbosa (2018) e Bulegon e Soares (2019). As reflexões feitas indicam que é imprescindível conhecer e valorizar o perfil sociolinguístico dos alunos, além de abrir espaço para que eles reflitam e promovam ações com reflexos diretos no cotidiano.

\section{Palavras-Chave}

PLAc. Warao. Abordagem comunicativa e intercultural.

\begin{abstract}
The goal of this article is to present an experience of teaching PLAc to the Warao indigenous people, in an extension project at the Federal University of Pará (from January to December of 2018). Since 2014, the Warao are migrating from Venezuela to Brazil because of the economic crisis in their country. In order to favor the relations between the Warao and the Brazilian society, we started to teach portuguese to them at the shelter where they lived. For the PLAc teaching, we used the communicative and intercultural approaches based on authors such as Caels (2016), Lopez (2016), Costa and Taño (2017), Cardoso (2018), São Bernardo and Barbosa (2018) and Bulegon and Soares (2019). The reflections made indicate that it is essential to know and value the students' sociolinguistic profile, as well as make room for them to reflect and promote actions with direct reflects in the daily life.
\end{abstract}

\section{KeYWORDS}

PLAc. Warao. Communicative and intercultural approach.

\footnotetext{
1 Doutora em Linguística pela University of Texas at Austin, e professora da Universidade Federal do Pará.

2 Graduando em Letras - Língua Portuguesa pela Universidade Federal do Pará.

3 Graduanda em Letras - Língua Portuguesa pela Universidade Federal do Pará
} 


\section{INTRODUÇÃo}

O objetivo deste artigo é relatar a experiência do projeto de extensão da Universidade Federal do Pará (UFPA): "Ensino de Português como língua de acolhimento (PLAc) para os indígenas Warao da Venezuela", que atendeu refugiados do abrigo Domingos Zahluth no bairro do Marco em Belém, no ano de 2018. O principal objetivo do ensino de PLAc para os indígenas Warao foi o de atender aos interesses dos indígenas em favorecer as relações com as várias esferas da sociedade brasileira. Sendo assim, foi adotada uma abordagem comunicativa e intercultural que possibilitasse uma troca de conhecimentos linguísticos e culturais entre os Warao e os voluntários do projeto (alunos da graduação do curso de Letras da UFPA). Além disso, foi possível promover uma reflexão sobre o ensino de PLAc para falantes indígenas e experiências de formação docente para os voluntários.

Os Warao são originários do Delta do Orinoco. Até 2017 a população era de aproximadamente 49.000 pessoas (RAMOS; BOTELHO; TARRAGÓ, 2017). A presença de indígenas Warao no Brasil tem sido registrada desde 2014 no Estado de Roraima (SILVA e TORELLY, 2018). Segundo Silva e Torelly (2018), o fluxo migratório foi mais notório na cidade de Manaus a partir do final de 2016 e, em Belém, a partir do final de 2017. Os autores mencionam que entre os motivos da migração dos Warao estão as condições precárias de sobrevivência em seus territórios tradicionais e a difícil situação desses indígenas no contexto urbano da Venezuela, principalmente após a crise nacional. Até o fim de 2018, a maioria era monolíngue em Warao (poucos jovens e adultos falavam e entendiam o espanhol). Eles aprendiam português apenas de maneira informal, ao se comunicarem com a comunidade externa no dia-a-dia.

Dentro desse contexto, o português era a segunda língua para a maioria e uma terceira língua para poucos. Consideramos que aprender português é importante para todos os imigrantes no Brasil, já que é a língua oficial do país. Acreditamos que a relevância social do projeto foi a de proporcionar aos Warao o início de um processo de capacitação através do ensino de uma segunda língua, enquanto um dever político e social. De acordo com Campetela (2014), o poder linguístico da fala e da escrita não é algo que se conquiste, mas algo que coexiste com a necessidade de se comunicar. Sendo assim, a fala e a escrita da maioria acaba sendo adotada pela minoria e a educação se torna um direito de todos. Contudo, esse processo de ensino não pode ser visto como obrigatório para os indígenas, já que o processo deve levar em conta as necessidades do contato dos mesmos com os falantes de português.

\section{Ensino de PLAC}

Segundo Costa \& Taño (2017), a necessidade de estudos e práticas sobre PLAc no contexto brasileiro deve-se ao aumento do número de refugiados no país. Podemos observar a crescente demanda, principalmente, no que diz respeito ao ensino de Português para venezuelanos. Segundo dados da Alto Comissariado das Nações Unidas para os Refugiados (ACNUR), há mais de 180 mil venezuelanos no Brasil, sendo a maioria indígenas da etnia Warao (700 indígenas em Belém atualmente). Diante deste contexto, enfrentamos vários desafios no que diz respeito a como ensinar PLAc para indígenas em sua maioria monolíngues na língua materna? Como realizar um aco- 
lhimento a partir da língua portuguesa sem deixar de valorizar sua cultura e língua materna? Que metodologia de ensino e materiais didáticos utilizar?

Tivemos dificuldade para encontrar uma metodologia de ensino que ajudasse na elaboração das aulas. Um dos motivos dessa dificuldade foi entender as especificidades de ensino de PLAc, que não segue a mesma linha de ensino de uma PLE, por exemplo (com a qual os voluntários do projeto tinham mais experiência). De acordo com Costa e Taño (2017), o curso de PLE geralmente é um curso feito por pessoas com interesses de lazer ou profissional, não há tanta urgência em se aprender uma segunda língua, e, por isso, os alunos dispõem de tempo para a realização do curso.

Já a PLAc é caracterizada pela necessidade emergencial da aprendizagem dessa segunda língua, visando a inserção dos refugiados e imigrantes no país, além de considerar também a inserção deles na cultura do país, sem que percam a identidade do seu país de origem. São Bernardo \& Barbosa (2018) também caracterizam o ensino de PLAc como um ensino voltado para imigrantes em situação de vulnerabilidade, que necessitam desenvolver práticas sociais que os ajudem a sobreviver no novo país. Há uma preocupação maior com a interculturalidade e com o ensino da língua em uso, utilizando-se temas que estão no cotidiano do imigrante (saúde, trabalho, dar e receber informações, alimentação). Caels (2016) também sugere ensinar por temas, investir na oralidade e, pelo caráter emergencial do curso, destinar um tempo curto para cada aula. $\mathrm{O}$ autor sugere ainda uma avaliação diferenciada no decorrer das aulas através de descritores de proficiência.

A maior parte da literatura existente na área é baseada em experiências de ensino de PLAc para refugiados de países do sudeste asiático, do oriente médio e do Haiti, como é o caso das experiências apresentadas em Costa \& Taño (2017), Soares \& Tirloni (2017) e Lopez (2016). Através da mídia, sabe-se de algumas iniciativas que oferecem o ensino de PLAc para venezuelanos não-indígenas, tais como um curso oferecido pela agência para refugiados (ACNUR) em parceria com a Universidade Federal de Roraima (UFRR), em Boa Vista, e recentemente um curso oferecido pelo Instituto Federal do Pará (IFPA), em Belém. Há ainda poucas iniciativas de ONGs e de outros grupos sociais que oferecem essas aulas para indígenas em Boa Vista e Manaus.

$\mathrm{Na}$ capital paraense, após a cobrança pelo Ministério Público Federal para que as instituições públicas tomassem providências, foi formada uma Comissão Institucional em 2018. A UFPA e a Universidade Estadual do Pará (UEPA) faziam parte da comissão. Paralelamente ao nosso projeto, a UEPA, conjuntamente com as secretarias do Estado e do município (SEDUC e SEMEC), havia elaborado um projeto de educação chamado Kuarika Naruki. Esse projeto também tinha como objetivo oferecer o ensino da língua portuguesa, mas através de outra proposta, como parte da educação escolar indígena. Até o fim de 2018, esse projeto de educação não havia sido implementado.

\section{Contexto do projeto de ensino de PLAc para os Warao}

A ideia de dar aulas para os indígenas Warao começou com a iniciativa de doar materiais escolares para o abrigo Domingos Zaluth, uma iniciativa organizada por professoras do curso de Letras da UFPA. Até então, não havia um planejamento para que os Warao fossem para a escola. Sendo assim, com a ajuda das professoras da UFPA Gessiane Picanço, Karina Gaya e Marília Freitas, e de Joshua Birchall (pesquisador do Museu Goeldi), a coordenadora do projeto começou a dar aula uma vez por semana no próprio abrigo. A ajuda de José Albarrán Lopez, intérprete e funcio- 
nário da Secretaria de Estado de Assistência Social, Trabalho, Emprego e Renda - SEASTER/PA (que trabalhava no abrigo) também foi fundamental durante os primeiros contatos com os Warao.

No início do projeto, em janeiro de 2018, moravam aproximadamente 50 indígenas Warao no abrigo, junto com outros refugiados venezuelanos não indígenas e pessoas oriundas de outros países. Ao final do projeto, o número dos que moravam no abrigo já havia dobrado, resultando em uma superlotação que prejudicou a continuação das aulas. Nesse contexto, os Warao passavam por dificuldades no abrigo, notadamente com relação à alimentação, pois não estavam acostumados com a alimentação dos não-indígenas, e com relação a local apropriado para dormir. A própria mistura de etnias causava conflitos no abrigo.

O espaço para a realização das aulas era improvisado. Era uma sala pequena, calorenta, sem divisórias nem porta, por onde havia o trânsito constante de pessoas (impedindo que houvesse silêncio no local). Quando chegávamos no local, a quantidade de cadeiras e mesas não era suficiente e precisávamos procurar por mais cadeiras. Além disso, muitas vezes, ocorria uma falta de comunicação dos funcionários do abrigo com os indígenas Warao, que não eram avisados sobre as aulas. Essas dificuldades atrasavam bastante o início das aulas e prejudicavam o aproveitamento das mesmas.

Nos últimos meses do projeto, quando já era impossível dar aulas no abrigo, devido à superlotação, procuramos outro local e, como não era viável para os indígenas assistir às aulas na universidade, já que o local ficava distante do abrigo, conseguimos o apoio da organização internacional filosófica Nova Acrópole, que cedeu salas de sua escola para nossas aulas. Como o número de alunos diminuiu com a mudança de local e devido à falta de apoio governamental na parte de infraestrutura, entre outros fatores, decidimos terminar o projeto em dezembro de 2018. A seguir, apresentaremos um perfil dos alunos que frequentavam as aulas no abrigo.

\section{O PERFIL dos Alunos}

A primeira turma iniciou com 18 alunos. Nessa época havia uma grande rotação de alunos, que, toda semana, entravam e saiam do grupo. Terminamos o primeiro semestre de 2018 com 10 alunos, todos homens, e desses, 6 permaneceram na turma A2 do segundo semestre. As mulheres não participaram dessa primeira turma, pois, trabalhavam muito cedo nas ruas como pedintes e à tarde tinham afazeres domésticos. Além disso, elas quase não entendiam espanhol, o que dificultava a comunicação. A turma A1 no segundo semestre teve em torno de 10 alunos, sendo 7 homens e 3 mulheres. Costa \& Taño (2017) também mencionam que no projeto realizado em São Paulo, a maioria era homens. A figura 1 mostra os alunos da primeira turma e figura 2 da turma A1. 


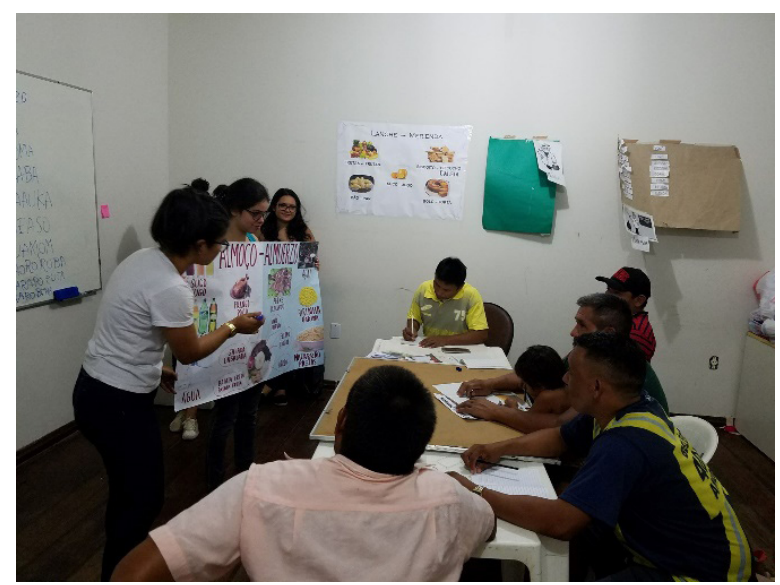

Figura 1

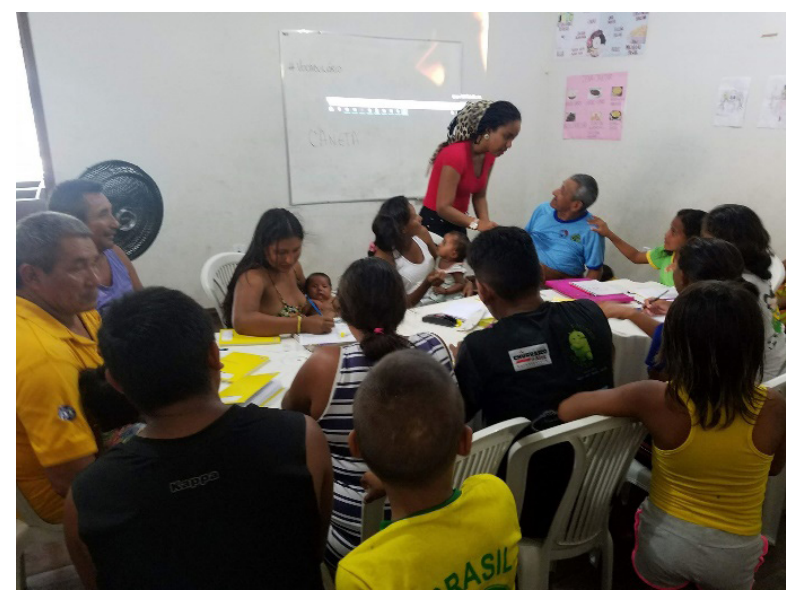

Figura 2

No segundo semestre elaboramos um questionário sociolinguístico ${ }^{4}$ que foi aplicado a 12 indígenas Warao. Os resultados sobre as informações pessoais dos alunos mostraram que a maioria era de adultos entre 20 e 40 anos (apenas três alunos tinha menos de 18 anos e um tinha 67 anos), provenientes de diferentes comunidades na Venezuela, entre elas: Araguabina, Narunoko, Kaigual, Kubaruna e Ubiruna. Os alunos que participaram da primeira turma estavam em Belém há quase 1 ano, enquanto outros haviam chegado há 2-3 meses.

Já as perguntas sobre a situação sociolinguística foram as seguintes: a) Você fala espanhol? (bem, mais ou menos ou pouco), b) Você entende português? (bem, mais ou menos ou pouco), c) Você foi alfabetizado em espanhol ou Warao? d) Com quantos anos começou a estudar? Até que idade? Também havia perguntas sobre o aprendizado de português, tais como: a) Há quanto tempo você estuda português? b) O que você espera ou esperava do curso? c) Em quais atividades do dia a dia você usa o português? d) Gostaria de ter mais aulas de português por semana?

O questionário foi aplicado tanto aos alunos que já estudavam português, quanto aos novos alunos, com o objetivo de avaliar seus conhecimentos do espanhol e do português. Além disso, observamos que a turma anterior apresentou muitas dificuldades para aprender e não teve um bom rendimento. Então, o questionário poderia indicar se eles realmente estavam sentindo a necessida-

4 O questionário usado no projeto teve por base o questionário apresentado em Lopez (2016). 
de de utilizar o português no dia a dia e como direcionar o curso para que o mesmo cumprisse com as expectativas desses alunos.

A análise das respostas ao questionário indica os seguintes resultados: a maioria falava bem o espanhol e entendia pouco o português; a maioria não foi alfabetizada e aqueles que foram alfabetizados frequentaram a escola por 5 a 7 anos; eles esperavam aprender português para conseguir emprego, traduzir quando necessário para seu povo, fazer compras ou conversar com não-indígenas dentro do abrigo; foram poucos os que falaram que já conversavam em português com não-indígenas no abrigo; a maioria não fazia uso do português; muitos sugeriram que as aulas fossem todos os dias ou pelo menos 3 vezes por semana. A partir dos resultados do questionário foi possível planejar melhor as aulas do segundo semestre.

\section{Os VOLUNTÁRIOS}

Para a seleção de voluntários, foram escolhidos alunos da graduação do curso de Letras - Língua Portuguesa e Línguas Estrangeiras Modernas da UFPA interessados em lecionar para indígenas. A maioria era bolsista do programa PET Letras, que já tinha envolvimento em projetos com indígenas (assim como a coordenadora do projeto) e tinha um perfil de pessoas abertas às diferenças socioculturais. Ao todo, participaram do projeto 12 voluntários ${ }^{5}$. No primeiro semestre, eram 8 voluntários que foram divididos nas duas oficinas ministradas para os Warao, ficando quatro na oficina de trabalho e quatro na oficina de alimentação. No segundo semestre, eram seis voluntários, três em cada turma. Os voluntários participavam de reuniões quinzenais sobre o projeto, realizando reflexões sobre as aulas, sobre os materiais didáticos e fazendo discussões sobre os textos relacionados aos Warao e a PLAc, com o intuito de adquirir mais conhecimento e embasamento para o planejamento e prática nas aulas. Eram selecionados três voluntários por vez para iniciar a explanação do material discutido na reunião. Os voluntários, também, eram responsáveis por montar os planos de aula das oficinas, produzindo, se necessário, slides para ilustração das aulas, selecionando imagens e vídeos para serem apresentados aos alunos e o material para as atividades realizadas em sala.

Antes de começarmos as aulas do segundo semestre, aplicamos um questionário avaliativo aos voluntários com as seguintes perguntas: a) Em que medida você acha que a didática do ensino de PLAc (como aquela em que você atua) se aproxima e/ou se afasta da didática de um curso de PLA para outros públicos ou, ainda, daquela de cursos de português como primeira língua? b) Que tipos de recursos didáticos você geralmente usa para conduzir as suas aulas de PLAc? c) No contexto de ensino de PLAc que você atua, há desafios na implementação/condução/organização das aulas? Quais?

As respostas nos ajudaram, principalmente, a identificar melhor os desafios e buscar soluções para os mesmos.

Com relação à didática do ensino de PLAc ser diferente das demais (com as quais os voluntários estavam acostumados), observou-se que a principal diferença foi o ensino de português para alunos não alfabetizados, mesmo sendo o projeto voltado para o ensino do português oral. Os voluntários ainda comentaram que usavam materiais didáticos próprios, elaborados a partir de

5 Agradecemos aos seguintes alunos que participaram como voluntários do projeto: Alice Braga, Ana Fonseca, Flávio Silva, Isadora Ribeiro, Marina Farias, Samily Soares, Tatiane de Aquino, Thaina Lima, Tonya Gonçalves, Viviane Cardoso e Yagma Figueira. 
outros materiais. A organização de um material eficiente para o público indígena foi vista como um desafio, já que a elaboração do mesmo tomava bastante tempo. Outros desafios apontados foram: dar aula em português, pois apenas duas voluntárias podiam se comunicar um pouco em espanhol com eles; entender as diferenças culturais e considerá-las em sala de aula; e dificuldades com a pouca infraestrutura para dar aula.

\section{Os MATERIAIS DIDÁTICOS}

A coordenadora e os voluntários do projeto eram responsáveis pela escolha e a produção de materiais didáticos, devido a escassez de artigos e materiais publicados que se enquadrassem no contexto de ensino para indígenas. Para as aulas, preparávamos slides com imagens e vídeos para ilustrar o assunto trabalhado, produzíamos cartazes com imagens, realizávamos atividades lúdicas, por exemplo, para ensinar as vogais, utilizamos atividades de recorte, de ligar uma palavra à vogal que a inicia. Todavia, nos baseamos em publicações que encontramos para a produção e para o planejamento das aulas, tais como: Português do Brasil para refugiadas e refugiados de Oliveira et al (2015) e Guia para o ensino de português enquanto Lingua de Acolbimento no contexto da educação não Formal (ENF) de Caels (2016).

O projeto de ensino de PLAc deu enfoque na oralidade, mas a partir do segundo semestre, também começou a desenvolver as competências de leitura e escrita, conforme solicitado pelos próprios alunos. Também pensamos que poderia ajudar no aprendizado, já que eles memorizavam melhor o vocabulário quando conseguiam escrever no caderno. Por isso, passamos a adotar ações de alfabetização para imigrantes de acordo com o método usado em Caels (2016).

\section{As oficinas}

As primeiras aulas ocorreram no período de janeiro a março de 2018, com um conteúdo introdutório sobre formas de apresentação, saudações e expressões cotidianas, dias da semana e meses, horas, números, como dar informações pessoais e como falar sobre atividades do cotidiano. As aulas ocorriam às terças-feiras pela manhã e sextas-feiras à tarde. É importante frisar que durante as explanações tentávamos comparar o português com o espanhol e a língua Warao para facilitar a aprendizagem. Isso também nos possibilitou aprender algumas palavras e expressões na língua indígena.

Durante essas primeiras aulas, nos foram apresentadas algumas necessidades por parte dos Warao. A primeira era de que eles fossem capazes de conseguir algum trabalho informal com esse vocabulário aprendido em sala de aula. Outra necessidade era a de aprender o vocabulário de comidas para que eles pudessem fazer compras no mercado, por exemplo. A partir de abril, tendo em vista essas duas necessidades imediatas, foram elaboradas duas oficinas ministradas pelos voluntários em dois grupos: uma oficina sobre trabalho e outra sobre alimentação. Além desses temas, os professores ensinavam o vocabulário que se adequava a tal assunto. As oficinas aconteciam às tardes, duas vezes na semana (uma em cada dia da semana) e tiveram dois meses de duração.

\section{Oficinas SObre trabalho E Alimentação}

$\mathrm{Na}$ oficina de trabalho foram abordados vários temas ligados a trabalho/emprego. Primeiramente foi ensinada a noção de dinheiro, já que é algo que eles lidam diariamente e também está 
relacionado a trabalho. Depois foram ensinados diferentes tipos de trabalho, tanto formal, que precisam de formação adequada (médico(a), advogado(a), professor(a), entre outros), quanto informal (feirante, ambulantes, descarregador(a) de mercadorias e outros). Ainda sobre esse assunto, como atividade lúdica ao final da aula, os alunos jogavam um jogo da memória no qual tinham que associar o objeto de trabalho com o trabalho correspondente.

Como já assinalado, o vocabulário da língua portuguesa era ensinado junto com os assuntos, sendo que os Warao aprendiam como pedir emprego em português, a dar o endereço do abrigo ou a se apresentar dando algumas informações pessoais como seu nome, lugar de origem, etnia e idade.

No fim da oficina foi realizada uma atividade que simulava uma entrevista de emprego. Nessa atividade eles tiveram que se apresentar e se candidatar a um cargo de qualquer trabalho dos que foram vistos durantes as aulas.

Durante as aulas da oficina de trabalho os alunos reconheciam trabalhos que eles já haviam realizado na Venezuela, como pedreiro, pintor, marceneiro e outros. Essa identificação foi muito importante pra eles entenderem que poderiam tentar esses trabalhos também em Belém. Outro fator que contribuiu para as aulas foi a motivação dos alunos.

Como eles necessitavam de dinheiro para ajudar em seus mantimentos, eles desejavam conseguir emprego. Dessa maneira, compreender o mínimo necessário da língua portuguesa, a noção da moeda nacional e um pouco sobre as leis trabalhistas do país era essencial como forma de evitar serem explorados ou enganados. Os alunos demonstraram empenho nas aulas, principalmente nas atividades práticas.

$\mathrm{Na}$ oficina de alimentação foram ensinadas referências às refeições diárias: café da manhã, almoço, lanche e jantar, e os alimentos correspondentes a cada um desses momentos. Como atividade foi realizado um bingo de alimentos, no qual eles deviam ouvir a palavra, reconhecer a imagem na cartela e marcá-la. As regras eram as mesmas do bingo e vencia quem primeiro preenchesse ela por completo. Foram feitos, também, cartazes com imagens dos alimentos com seus respectivos nomes escritos em português e espanhol, para ajudar no entendimento.

No segundo semestre de 2018, três voluntários continuaram e três novas voluntárias entraram no projeto. A partir dos resultados dos questionários aplicados com os Warao e voluntários, foi possível concluir que deveriam ser formadas duas turmas: uma de iniciantes com uma maioria de alunos não alfabetizados (A1) e outra com alunos mais avançados e alfabetizados (A2). Verificamos também que o maior problema enfrentado pelos alunos para aprender português era o fato de que raramente colocavam em prática o que aprendiam. As aulas continuaram acontecendo duas vezes por semana, pois não foi possível aumentar carga horária com a criação de uma nova turma.

Ainda com o objetivo de verificar quais alunos da turma anterior tinham condições de passar para a turma A2, elaboramos atividades de nivelamento com descritores avaliativos. As atividades eram realizadas em grupos de três pessoas, sendo utilizados os seguintes descritores avaliativos: excelente, quando havia facilidade ou pouca dificuldade para responder às perguntas; bom, quando o aluno apresentava algumas dificuldades para responder às perguntas; regular, quando havia muitas dificuldades para responder e insuficiente, quando o aluno não conseguia responder. 
Apenas para citar um exemplo, uma das atividades tinha como objetivo verificar a habilidade de associar os horários com a alimentação. Na Etapa 1 da atividade, os alunos tinham que associar as imagens das refeições (café da manhã, almoço, lanche e jantar) com os horários que eles devem ser consumidos em um cartaz. Na etapa 2, eles deveriam identificar os alimentos consumidos em cada refeição nas fotos. Os nomes dos alimentos eram mostrados em papéis para que eles colocassem nos cartazes e pronunciassem. Nessa atividade usamos os seguintes descritores avaliativos: a) excelente: facilidade para associar a alimentação com o horário; identificou os alimentos e pronunciou os nomes dos mesmos; b) bom: teve alguma dificuldade em associar a alimentação com o horário, em identificar os alimentos e em pronunciar os nomes dos mesmos; c) regular: teve muita dificuldade em associar a alimentação com o horário, em identificar os alimentos e em pronunciar os nomes dos mesmos; d) insuficiente: não conseguiu associar a alimentação com o horário, identificar os alimentos nem pronunciar os nomes dos mesmos.

Com base nessas atividades de nivelamento, foi possível detectar que sete dos nove alunos que realizaram as atividades, poderiam passar para turma A2. Os descritores avaliativos foram muito importantes para mostrar o rendimento dos alunos. Sendo assim, passamos a adotar os descritores em todas as atividades desenvolvidas em sala de aula. Infelizmente, tivemos que repensar esta organização das turmas com base no conhecimento que já tinham, pois alguns alunos se recusaram a estar em uma turma por estarem separados de seus parentes que estavam em outra turma.

\section{Aulas para iniciantes $A_{1}$}

A turma A1 seguiu a mesma ementa da turma anterior, com conteúdos introdutórios. O planejamento das aulas levava em consideração o desenvolvimento das seguintes competências: comunicativa intercultural, linguística (léxico e gramática), de compreensão e produção oral, e compreensão e produção escrita (cf. CARDOSO, 2018).

A seguir, iremos descrever uma sequência de aulas para essa turma elaborada com base nos aspectos pedagógicos para ações de alfabetização de imigrantes, propostos por Caels (2016). Segundo Caels, a planificação deve envolver algumas etapas, entre as quais estão: a) introdução; b) leitura partilhada de história; c) introdução à discussão oral de palavras referentes ao vocabulário da história; d) leitura e escrita global de palavras e) elaboração oral e escrita de uma frase simples.

A carga horária de cada aula era 1 h e $15 \mathrm{~min}$, e três voluntários estavam responsáveis em elaborar e aplicar as atividades. O tema da primeira sequência de aulas era Conhecendo Belém, composta por cinco aulas. Os objetivos dessa unidade foram desenvolver a competência comunicativa e intercultural, de compreensão/produção oral e compreensão/produção escrita de palavras relacionadas à alimentação, além de conhecer aspectos da cultura paraense. Os conteúdos trabalhados foram:

a) Competência intercultural/ comunicativa/produção oral: interação inicial com a turma para saber se eles conhecem as comidas típicas e frutas de Belém e diálogo a partir de vídeo. Discussão de semelhanças e diferenças de Belém com relação à comunidade onde moravam na Venezuela. Apresentação de situação de compra de frutas para mostrar para os alunos as moedas e cédulas de reais e comparar com os bolívares soberano;

b) Competência lexical: introdução de vocabulário de comidas paraenses e frutas, através de imagens com os nomes em slides projetados no data show; 
c) Compreensão/produção escrita: respostas às atividades de escrita de nomes em imagens e frases;

d) Competência de compreensão escrita: textos curtos sobre frutas.

e) Competência linguística: pronomes possessivos (meu(s)/minha(s), nosso(s)/nossa(s)).

As sequências de atividades, em geral, buscavam integrar tanto elementos lúdicos como mais técnicos. Na sequência de aulas apresentada, há vídeos, diálogo, jogos para memorizar vocabulário, mas também atividades de leitura e escrita. Por exemplo, uma atividade de revisão foi o jogo do prato com as frutas. Pedimos para os alunos separarem as imagens de frutas que começavam com as letras $a, b$ e $c$ em cada ficha e colocarem os nomes das frutas que começam com cada letra. Depois eles recortaram os nomes, e em grupos tinham que colocar o nome que era pronunciado pelo professor no prato. O grupo que colocasse mais nomes de forma correta no prato ganhava. Observamos que os Warao apresentavam um desempenho melhor nas atividades relacionadas à produção oral e escrita de palavras isoladas ou em frases, e de fixação de vocabulário. Eles tinham mais dificuldades para realizar atividades de compreensão escrita de textos e sobre gramática.

\section{Aulas para a turma de $\mathbf{A}_{2}$}

Com relação à turma de A2, com alunos alfabetizados, a ementa tinha como objetivo conhecer as manifestações culturais brasileira e valorizar a identidade Warao através dos gêneros textuais contos e lendas amazônicas e narrativas tradicionais. Escolhemos os gêneros contos e lendas amazônicas, pois apresentam a característica da oralidade, além de elementos e estruturas que podem ser comparados às narrativas tradicionais Warao. A carga horária dessa turma era de $1 \mathrm{~h}$ e $30 \mathrm{~min}$ e também era ministrada por três voluntários. Durante algumas aulas contamos com a participação de um dos alunos Warao, que era mais fluente em espanhol e entendia razoavelmente o português, para explicar em Warao alguns termos e atividades realizadas na sala de aula.

Iremos descrever a sequência de aulas com o tema $A$ lenda do açaí, composta por quatro aulas. Os objetivos da unidade eram desenvolver a competência comunicativa e intercultural, ampliar as capacidades de compreensão/produção oral e compreensão/produção escrita, além de conhecer a lenda do açaí e comparar com uma narrativa Warao sobre a fruta. Os conteúdos trabalhados foram:

a) Competência intercultural/comunicativa/produção oral: interação inicial com a turma sobre as lenda da Amazônia e as narrativas tradicionais Warao. Apresentação de um resumo oral da lenda do açaí em espanhol e de vídeo. Interação inicial com a turma para saber se gostam de música, que tipo, se tem músicas em Warao. Falar sobre a música Sabor açaí e passar o vídeo da música;

b) Competência lexical: introduzir vocabulário necessário para que os alunos compreendam a história ao ler, a música Sabor açaí e o vocabulário de frutas regionais;

c) Compreensão e produção escrita: texto adaptado (mais curto) com a lenda e com a música em português. Respostas às atividades de compreensão da lenda e da música;

d) Competência linguística: vogais orais.

Durante a primeira aula da sequência, percebemos que os alunos não conheciam muito bem as narrativas tradicionais de seu povo. Descobrimos que eles tinham uma narrativa semelhante à lenda do açaí, que um dos alunos contou em espanhol. Pedimos para que eles pesquisassem sobre essas histórias com os mais velhos. Assim como foi feito com a turma A1, misturamos atividades mais lúdicas com mais técnicas. Os alunos gostavam de ver vídeos e escutar músicas durante as 
aulas. Os alunos estavam bastante motivados a aprenderem os sons das vogais, quando começamos a apresentar as vogais para que eles identificassem as mesmas nas palavras da música. Eles diziam que essa forma de ensinar era mais parecida com o método utilizado nas escolas onde estudaram.

Nas atividades de compreensão e produção escrita, a maioria apresentava dificuldades na aprendizagem da leitura, mesmo sendo alfabetizados. Para facilitar a aprendizagem e motivá-los, criamos atividades, tais como, dar aos alunos partes da história em um pedaço de papel para organizarem segundo a ordem da história. Houve uma tentativa de introduzir o vocabulário de frutas regionais para que eles utilizassem no dia-a-dia, mas o tema das lendas dificultou abordar tópicos e vocabulário para uso imediato. Essas dificuldades de aprendizagem, entre outras dificuldades, levaram à desmotivação de alguns alunos depois de dois meses. Acreditamos que a maioria dos nossos objetivos teriam sido alcançados se a sala de aula tivesse sido um espaço para mais reflexões e promoção de ações. Por exemplo, os Warao estavam participando de reuniões para a elaboração de um protocolo de recebimento dos imigrantes indígenas, um tema que infelizmente não foi abordado em sala de aula.

\section{CONSIDERAÇÕES FINAIS}

Este artigo buscou compartilhar experiências da prática de PLAc com indígenas Warao, já que há uma crescente demanda por mais cursos para esse público, principalmente nos estados de Roraima, Amazonas e Pará. Ao longo do projeto percebemos que, ao mesmo tempo que é necessário promover o português como língua de acolhimento, é necessário desenvolver mais políticas linguísticas que valorizem as línguas minoritárias, faladas por esses imigrantes refugiados. Como afirmam Bulegon e Soares (2019), o Brasil apesar de ser um país plurilíngue com mais de 150 línguas indígenas e comunidades de imigrantes (falantes de italiano, alemão, japonês, entre outras línguas), possui políticas linguísticas precárias, que não promovem um real acolhimento desses novos imigrantes.

Sendo assim, iniciativas voltadas para os imigrantes, tais como projetos e programas nas universidades, são fundamentais para conscientizar a comunidade acadêmica sobre essa realidade. A principal contribuição do projeto foi a de proporcionar uma troca de saberes entre os Warao e os voluntários. Alguns voluntários da UFPA mencionaram que passaram a entender e respeitar mais os imigrantes depois de conhecê-los e saber da situação em que vivem. Os questionários e as conversas com os Warao antes, durante e depois das aulas nos auxiliaram a planejar o curso de acordo com as necessidades que eles apresentavam.

Portanto, consideramos que a valorização do perfil sociolinguístico dos alunos indígenas, das línguas que falam e de suas culturas, é imprescindível para o sucesso das aulas de PLAc para imigrantes (indígenas e não-indígenas). Além disso, nesse contexto de crise política e econômica no Brasil (nos quais os direitos dos povos indígenas do próprio país estão ameaçados), o objetivo principal do curso deveria ser promover o conhecimento sobre as leis, direitos e deveres, entre outros assuntos que permitam aos imigrantes indígenas aprenderem a ser críticos e reivindicar seus espaços na sociedade.

\section{REFERÊNCIAS}

BULEGON, M.; SOARES, L. F. Impactos sociais dos novos fluxos migratórios e políticas linguísticas no 
Brasil: o ensino de Português como Língua de Acolhimento (PLAc). Revista on line de Política e Gestão Educacional, Araraquara, v. 23, n. 3, 2019, p. 638-655.

CAELS, F. Guia para o ensino de português enquanto Língua de Acolhimento no contexto da educação não formal (ENF). Lisboa: ACM, IP, 2016.

CAMPETELA, C. Proposta de material didático para ensino e aprendizagem do português como segunda língua em escolas indígenas. Letras Escreve, v. 4, n. 1, 2014.

CARDOSO, S. As lendas da Amazônia como recurso de ensino-aprendizagem intercultural de Português Língua Estrangeira. Faculdade de Letras da Universidade do Porto, 2018.

COSTA, E.; TAÑO, R. Ensino de português como língua de acolhimento a imigrantes e refugiados em São Paulo. Revista CBTecLE, São Paulo, v. 1, n. 2, 2017.

LOPEZ, A. P. A. Subsídios para o planejamento de cursos de português como língua de acolhimento para imigrantes deslocados forçados no Brasil. Dissertação (Mestrado em Letras). Faculdade de Letras, Universidade Federal de Minas Gerais. 260 f. Belo Horizonte, 2016. Disponível em: http:// bit.ly/2NhjT4Y. Acesso 20 agosto 2018.

OLIVEIRA, T. [et al]. Pode entrar: Português do Brasil para refugiadas e refugiados. 1. ed., São Paulo, 2015. RAMOS, L.; BOTELHO, E.; TARRAGÓ, E. Sobre a situação dos indígenas da etnia Warao, da região do delta do Orinoco, nas cidades de Boa Vista e Pacaraima. Parecer Técnico n. 208/2017/ Seap/6aCCR/ PFDC. Brasília: Procuradoria-Geral da República, 2017.

SÃO BERNARDO, M.; BARBOSA, L. Ensino de português como língua de acolhimento: uma experiência em um curso de português para imigrantes e refugiados(as) no Brasil. Fólio- Revista de Letras, Vitória da Conquista, v.10, n.1, 2018, p. 475-493.

SILVA, S.; TORELLY, M. (Orgs.). Diagnóstico e avaliação da migração indígena da Venezuela para Manaus, Amazonas. Brasilia: Organização Internacional para as Migrações (OIM), Agência das Nações Unidas para as Migrações, 2018.

SOARES, L.; TIRLONI, L. Rakonte mwen: um projeto de ensino de português brasileiro a imigrantes haitianos a partir da literatura popular. Revista X, Curitiba, v. 12, n. 2, 2017. 